\title{
Area Studies Liaison Group at Work
}

APSA Area Studies Liaison Group

In early 1999, APSA asked the several area studies associations to appoint representatives to a newly created Area Studies Liaison Group (ASLG). The ASLG's central purpose is to improve communication among political scientists specializing in international relations and comparative politics whose scholarship centers on one or more world regions. A particular objective is to enhance participation in APSA by political scientists working in areas that have less influence on the shape of the discipline than they may merit. As such, the ASLG forms a discrete and significant element in APSA's season of strategic planning, one objective of which is to restore growth in the Association's membership.

Members of the ASLG include Harvey Feigenbaum, George Washington University (European Studies); John Harbeson, City University of New York (African Studies Association); Mervat Hatem, Howard University (Middle Eastern Studies); Cynthia McClintock, George Washington University (past president, Latin American Studies Association); and Carol Nechemias, Pennsylvania State University (Slavic Studies). The group is seeking individuals to represent Asian Studies, Canadian Studies, and, possibly, American Studies.

The ASLG's central strategic focus upon increased recognition within the discipline of the contributions to theory by comparativists and international relations scholars working primarily in one or more world regions has been shaped by various trends within APSA. First, whereas $64 \%$ of APSA members choose international relations and comparative politics as one of their fields, in 1999, only 12 of the 43 divisions on the Annual Meeting Program Committee had an explicit comparative or international relations focus and those divisions were responsible for $37 \%$ of the panels. ${ }^{1}$ In addition, 18 related groups organized panels for the annual meeting on comparative and international topics.

Second, broad themes defining these subfields of political science have continued to be shaped disproportionately by specialists in European and American politics, while important contributions by specialists in other world regions have received less attention than they deserve. In particular, committee members agree that the recent debate over the condition of "area studies" has exacerbated this imbalance by underemphasizing these contributions.

The ASLG has been seeking a range of strategic means for communicating this message within the framework of the APSA. These initiatives have included:

* Working with the program chairs of APSA's 2000 Annual Meeting, Ira Katznelson and Helen Milner, who double as chairs of APSA's new State of the Discipline study in order to enhance participation by comparativists and international relations specialists working in underrepresented regions;

* Organizing a roundtable for the 2000 APSA meeting at which senior scholars will highlight theoretical contributions by regional specialists that have been less influential than they may deserve to be. Lucian Pye will discuss Asian specialists' contributions; Guillermo O’Donnell, Lantin Americanists' ones; Goran Hyden, Africanists' ones; Valerie Bunce, Eurasianists' ones; and Peter Katzenstein, Europeanists' ones.

* Informing the various area studies associations of its objectives and activities in a bid to stimulate greater participation by political scientists belonging to those associations in the work of the APSA.

* Identifying comparativists and international relations specialists working in a variety of world regions who could be candidates to serve on the APSA Council and other key APSA committees and in positions such as the next editor of the APSR.

* Identifying candidates for special Annual Meeting lectures such as the Ithiel de Sola Pool lecture, next scheduled for 2001 .

* Proposing a new organized section that would appeal to comparativist members of APSA who do not belong to the comparative politics section. Only 1580 of the 8664 members identifying themselves as comparativists belong to the existing organized section.

* Seeking ways to promote the internationalization of the APSA. The group supports APSA's efforts to increase the trend toward an increasingly international membership.

The ASLG is a highly motivated group. It has received splendid support from the APSA. Its members look forward to receiving ideas, insights, and suggestions from the several area studies association constituencies in response to what it has done to date.

\section{Note}

1. This number is problematic since some panels are cosponsored, divisions that are not explicitly comparative or international do accept some papers and arrange some panels that have a comparative focus, and poster sessions are not included here. 